\title{
Effect of a Selective Endothelin Receptor A Blocker on Cardiovascular Remodeling in Uninephrectomized Spontaneously Hypertensive Rats of the Stroke-Prone Strain
}

\author{
Stephan R. Orth ${ }^{a}$ Günter Schiele ${ }^{b} \quad$ Bernhard Banas $^{a} \quad$ Eberhard Ritz ${ }^{b}$ \\ Kerstin Amann ${ }^{c}$ \\ a Department of Internal Medicine II, University of Regensburg, Regensburg, \\ ${ }^{b}$ Department of Internal Medicine, Ruperto Carola University Heidelberg, Heidelberg, and \\ 'Department of Pathology, University of Erlangen-Nürnberg, Erlangen, Germany
}

\section{Key Words}

Endothelin · Hypertrophy, left ventricular · Arterioles, intramyocardial $\cdot$ Hypertension - Receptor antagonist, endothelin $\cdot$ Rats, inbred SHRsp

\begin{abstract}
Background/Aims: The role of endothelin (ET) in cardiovascular remodeling was investigated by treating uninephrectomized spontaneously hypertensive rats of the strokeprone strain (UNX-SHRsp) on normal- or high (3\%)-salt diet with the selective $\mathrm{ET}_{\mathrm{A}}$ receptor blocker LU 135252. Methods: SHRsp on normal or high salt were sham-operated $(n=10 / 11)$ or UNX; UNX received no treatment $(n=10 / 15)$ or $100 \mathrm{mg} / \mathrm{kg}$ body weight LU $135252(n=10 / 10)$. Systolic blood pressure (BP) was measured weekly. After perfusion fixation the heart and the aorta were analyzed using quantitative morphological and stereological techniques. Results: No effect was seen in normal-salt groups. In high-salt animals UNX caused left ventricular (LV) hypertrophy which was prevented by LU 135252 ( $p<0.001)$. LU 135252 only lowered BP during the last 2 weeks of the 12-week experiment. UNX showed hypertrophic remodeling of intramyocardial arterioles. Treatment with LU 135252 caused lower wall:Iumen ratio and wall thickness of LV intramyocardial arterioles $(p<0.01)$. In the de-
\end{abstract}

scending thoracic aorta UNX caused thickening of the media. The media area and the wall:lumen ratio were lower in UNX + LU 135252 as compared to untreated UNX ( $p<0.01$ and $p<0.05$, respectively). Conclusion: In SHRsp UNX causes hypertrophic cardiovascular remodeling only in the presence of salt loading. These effects are largely BP-independent and prevented by $\mathrm{ET}_{\mathrm{A}}$ receptor blockade.

Copyright $\odot 2007$ S. Karger AG, Basel

\section{Introduction}

The cardiac dysfunction in hypertensive states is not only due to structural alterations of large vessels, i.e. coronary conduit arteries, but at least in part also to microvessel disease. Several studies suggest a role of local blood pressure (BP)-independent systems in these processes, particularly the renin-angiotensin-aldosterone and the endothelin (ET) systems. There is increasing evidence that the ET system plays an important role in the genesis of hypertension-induced target organ damage [1]. ET receptor blockade was shown to be effective in preventing mortality as well as cardiac and renal sequelae of hypertension in most, but not all experimental models of hypertension [2].

\section{KARGER}

Fax +41613061234 E-Mail karger@karger.ch www.karger.com

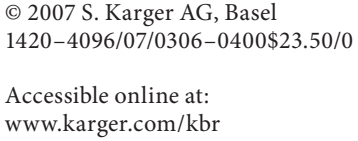


The salt-loaded uninephrectomized (UNX) spontaneously hypertensive rat of the stroke-prone strain (SHRsp) appears particularly suited to investigate a potential role of the ET system in cardiovascular remodeling, since dietary salt loading increases cardiac expression of preproET-1 mRNA in SHRsp [3]. Using this model we documented that treatment with the orally active and highly selective $\mathrm{ET}_{\mathrm{A}}$ receptor antagonist LU 135252 completely prevents renal damage and death [4]. Using the same model we now studied whether LU 135252 interferes with (1) left ventricular hypertrophy (LVH), (2) cardiac fibrosis, (3) thickening of intramyocardial arterioles, (4) capillary length density and (5) thickening of the descending thoracic aorta. This is the first report about the effects of selective $\mathrm{ET}_{\mathrm{A}}$ receptor blockade on these cardiovascular parameters in the salt-loaded UNX-SHRsp.

\section{Methods}

\section{Animals and Experimental Design}

Male 90- to 100-gram SHRsp (Iffa Credo, France) were housed in single cages at constant room temperature $\left(21^{\circ} \mathrm{C}\right)$ and humidity $(75 \%)$ under a controlled light-dark cycle. The rats were fed either a normal $(0.25 \% \mathrm{NaCl})$ - or a high-salt $(3 \% \mathrm{NaCl})$ diet (ssnif Spezialdiäten, Soest, Germany). The protein content of the food was $19 \%$. After a 7-day adaptation period the animals on normal and high salt were randomly allotted to three groups each ( $\mathrm{n}=$ 10-15): (1) sham-operated, control (sham-op), (2) uninephrectomized, no treatment (UNX), and (3) uninephrectomized + LU 135252 (UNX + LU 135252).

Anesthesia for uninephrectomy (UNX), sham-op and retrograde perfusion fixation (see below), respectively, was performed by intramuscular injection of ketamine (100 mg/kg body weight) and xylazine ( $5 \mathrm{mg} / \mathrm{kg}$ body weight). Because there was no significant change of any of the parameters after UNX and treatment with LU 135252 in the animals on normal-salt diet, the data are not reported in detail. The data of the UNX group on normal salt are reported as an additional control group to illustrate the effects due to a high-salt diet.

Treatment with the selective $\mathrm{ET}_{\mathrm{A}}$ receptor antagonist $\mathrm{LU}$ $135252\left(\right.$ for $\mathrm{ET}_{\mathrm{A}}$ receptor $\mathrm{Ki}=1.4 \mathrm{nmol} / \mathrm{l}$; for $\mathrm{ET}_{\mathrm{B}}$ receptor $\mathrm{Ki}=$ $184 \mathrm{nmol} / \mathrm{l}$ [5]) in the food was started 3 days before surgical ablation of the right kidney. The concentration in the food was calculated to deliver a daily dose of $100 \mathrm{mg} / \mathrm{kg}$ body weight. Daily food consumption was measured to control the amount of LU 135252 ingested. Water was offered ad libitum. Systolic BP was measured weekly by tail plethysmography. The normal-salt experiment was terminated after 18 weeks. In contrast, the high-salt experiment had to be terminated after 12 weeks due to excessive mortality in untreated UNX animals. Eight weeks into the experiments, a 24 hour urine collection was performed and blood samples were obtained. The experiments were terminated by retrograde perfusion using glutaraldehyde fixative via the abdominal aorta at a controlled pressure of $110 \mathrm{~mm} \mathrm{Hg}$, as described in detail elsewhere [6]. Blood and urine parameters were measured with a Hitachi 9-
17E, according to the manufacturer's guidelines. ET-1 plasma concentrations were measured in duplicate by enzyme immunoassay (Biomedica, Vienna, Austria), according to the manufacturer's guidelines.

Tissue Preparation and Morphological Investigations

Preparation of the heart and aorta for morphological investigations was performed as previously described in detail [6]. In brief, the heart of each animal was prepared and analyzed according to the orientator method [7]. Uniform random sampling of the myocardium was achieved by preparing a set of equidistant slices of the left ventricular (LV) and the interventricular septum with a random start. Two slices were selected by area-weighted sampling and processed accordingly. Eight pieces of the LV muscle (of each animal) including the septum were prepared and embedded in Epon-Araldite. Semithin sections $(0.8 \mu \mathrm{m})$ were stained with methylene blue and basic fuchsin and examined by light microscopy with oil immersion and phase contrast at a magnification of 1,000. All investigations were performed in a blinded manner, i.e. the observer was unaware of the study group the animal belonged to. Volume density $\left(\mathrm{V}_{\mathrm{V}}\right)$ of capillaries, interstitial tissue and myocytes was obtained using the point counting method according to the equation $P_{P}=V_{V}$ (where $P_{P}$ is point density). Reference volume was the total myocardial tissue (exclusive of noncapillary vessels, i.e. arterioles and veins, and tissue clefts). Vascular geometry of intramyocardial arterioles, i.e. vessels with lumen diameters between 20 and $120 \mu \mathrm{m}$ and at least one muscular layer, was analyzed using planimetry and a semiautomatic image analysis system (Analysis, SIS, Münster, Germany) as described in detail [6]. Thereby, mean wall thickness, lumen diameter, wall and lumen area were determined in every arteriole that was present in the 8 semithin sections per animal.

A 1-mm-thick piece of the aorta thoracica descendens was cut perpendicular to the vessel axis, embedded in Epon-Araldite and cut into $1-\mu \mathrm{m}$-thick semithin sections. Wall thickness and media area were measured using planimetry and a semiautomatic image analysis system (Analysis, SIS, Münster, Germany).

\section{Statistical Analysis}

Data are given as mean \pm SD. Statistical analysis was performed using one-way ANOVA, followed by the Bonferroni multiple range test or Kruskal-Wallis followed by Dunn multiple range test, as appropriate. The zero hypothesis was rejected at $\mathrm{p}<0.05$.

\section{Results}

\section{Characterization of the Model}

Body weight was comparable in the groups on normal salt (data not shown). Table 1 shows that body weight of sham-op rats on high-salt and treated UNX rats on highsalt diet was comparable, while it was significantly lower in untreated UNX rats on high salt, because the latter had failed to gain weight beyond the 10th week of the experiment. Systolic BP increased continuously in all three groups on normal and high salt during the experiment. No differences between the three groups on normal salt were 
Table 1. BP, plasma creatinine, urinary sodium excretion, body weight and LV weight:body weight ratio at the end of the experiment (week 12 for high salt, week 18 for normal salt)

\begin{tabular}{lllllll}
\hline Group & $\begin{array}{l}\text { Systolic } \\
\text { BP, mm Hg }\end{array}$ & $\begin{array}{l}\text { Plasma creati- } \\
\text { nine, mol/l }\end{array}$ & $\begin{array}{l}\text { Plasma ET-1 } \\
\text { fmol/ml } / \mathrm{ml} \text { excretion }\end{array}$ & $\begin{array}{l}\text { Body } \\
\text { urine, mmol/24 h }\end{array}$ & $\begin{array}{l}\text { LV, weight:body } \\
\text { weight, g }\end{array}$ & weight ratio, mg/g \\
\hline Sham-op (high salt; $\mathrm{n}=11$ ) & $270 \pm 16^{\mathrm{b}}$ & $38 \pm 4.69^{\mathrm{c}}$ & $5.9 \pm 1.9$ & $7.07 \pm 0.59$ & $279 \pm 22^{\mathrm{a}}$ & $3.50 \pm 0.18^{\mathrm{c}}$ \\
UNX (normal salt; $\mathrm{n}=10)$ & $281 \pm 13$ & $54 \pm 6.38$ & $4.8 \pm 1.3$ & $1.30 \pm 0.38^{\mathrm{d}}$ & $277 \pm 18$ & $4.22 \pm 0.28$ \\
UNX (high salt; $\mathrm{n}=$ 9) & $288 \pm 10$ & $52 \pm 6.81$ & $4.9 \pm 1.8$ & $7.50 \pm 1.51$ & $244 \pm 37$ & $4.16 \pm 0.21$ \\
UNX + LU 135252 (high salt; $\mathrm{n}=10)$ & $271 \pm 14^{\mathrm{b}}$ & $40 \pm 2.68^{\mathrm{c}}$ & $4.7 \pm 0.6$ & $6.60 \pm 1.43$ & $286 \pm 14^{\mathrm{a}}$ & $3.52 \pm 0.21^{\mathrm{c}}$ \\
\hline
\end{tabular}

Plasma ET-1 concentration was determined at week 8. A dose of $100 \mathrm{mg} / \mathrm{kg}$ body weight of LU 135252 was administered. Values are mean \pm SD. ${ }^{\mathrm{a}} \mathrm{p}<0.05 ;{ }^{\mathrm{b}} \mathrm{p}<0.01 ;{ }^{\mathrm{c}} \mathrm{p}<0.001 \mathrm{vs.} \mathrm{UNX}$ (high salt); ${ }^{\mathrm{d}} \mathrm{p}<0.001 \mathrm{vs}$. all high-salt groups. Due to a different duration of the normal- and high-salt experiments statistical analysis does not include the UNX normal-salt group; the latter is given for comparison.

observed (data not shown). High-salt diet did not further increase BP (table 1). Salt loading was comparable in all groups on high salt diet as reflected by similar urinary sodium excretion (table 1). BP in the high-salt groups was comparable until week 10. During the last 2 weeks BP was slightly, but significantly lower in the sham-op and treated UNX groups (table 1). Mortality during the 12 weeks of the experiment was $40 \%$ in untreated UNX-SHRsp on high salt; there were no deaths in the other groups on high salt and in the normal-salt animals, respectively.

At the end of the experiment plasma creatinine concentration was significantly higher in untreated UNX compared to sham-op or LU 135252-treated UNX animals on normal or high salt. No differences were observed with respect to plasma ET-1 concentrations (table 1) or hematocrit (data not shown).

\section{Heart Weight:Body Weight Ratio}

No differences were found in normal salt animals. The ratio of LV weight (after perfusion) to body weight was significantly higher in the groups of untreated UNX compared to sham-op or LU 135252-treated UNX animals on high salt. UNX on high salt treated with LU 135252 did not significantly differ from sham-op controls on high salt (table 1).

\section{Structural Changes of the Heart}

The histologic parameters of the heart investigated did not differ in the three groups on normal salt (data not shown). Because of insufficient perfusion leading to artifacts of the preparations, the stereological measurements could not be performed in 1 animal of the high-salt UNX and the high-salt UNX + LU 135252 groups, respectively.
Nonvascular Interstitial Tissue and Capillary Length Density

Significant intergroup differences of the volume density $\left(\mathrm{V}_{\mathrm{V}} ; \%\right)$ of nonvascular interstitial tissue were noted in high-salt animals, i.e., $2.01 \pm 0.43$ in the sham-op group; $3.72 \pm 0.85$ in the untreated UNX group ( $p<$ 0.001 vs. sham-op), and $3.32 \pm 0.43$ in the UNX + LU 135252 group ( $\mathrm{p}<0.001$ vs. sham-op). Electron microscopy revealed that the nonvascular interstitial tissue consisted mainly of collagen (not shown). Capillary length density $\left(\mathrm{L}_{V} ; \mathrm{mm} / \mathrm{mm}^{3}\right)$ was lower in high-salt as compared to normal-salt animals. It was not different in the three groups on normal salt (data not shown). Treatment with LU 135252 did not affect capillary length density, irrespective of dietary sodium content. The respective values for the high-salt animals are: 2,788 \pm 291 in shamop, 3,012 \pm 801 in untreated UNX and 3,063 \pm 517 in UNX + LU 135252 .

\section{Intramyocardial Arterioles}

Figure 1 shows representative examples of intramyocardial arterioles in sham-op rats on high salt (fig. 1a), untreated UNX on normal (fig. 1b) and high salt (fig. 1c), and UNX + LU 135252 animals on high salt (fig. 1d). Table 2 shows the structural parameters of intramyocardial arterioles, i.e. wall:lumen ratio, wall thickness, lumen diameter, and wall area. While lumen diameter was similar in all the normal-salt and high-salt groups, in salt-loaded animals UNX caused significant thickening of the arteriolar wall, thus leading to an increase in the wall:lumen ratio as seen in hypertrophic remodeling. Treatment with LU 135252 completely prevented these structural alterations (table 2). 
Fig. 1. Structural changes of small intramyocardial arteries in UNX-SHRsp on a high-salt diet 12 weeks after the start of the experiment. Representative arteriolar sections of sham-op SHRsp on high salt (a), untreated UNX-SHRsp on normal (b) and high salt (c), and LU 135252-treated UNXSHRsp on high salt (d). Note arteriolar wall thickening with hypertrophy of VSMC and reduced lumen area in untreated UNX-SHRsp on high salt (c), which was not seen when animals were treated with the $\mathrm{ET}_{\mathrm{A}}$ receptor blocker $(\mathbf{d})$.
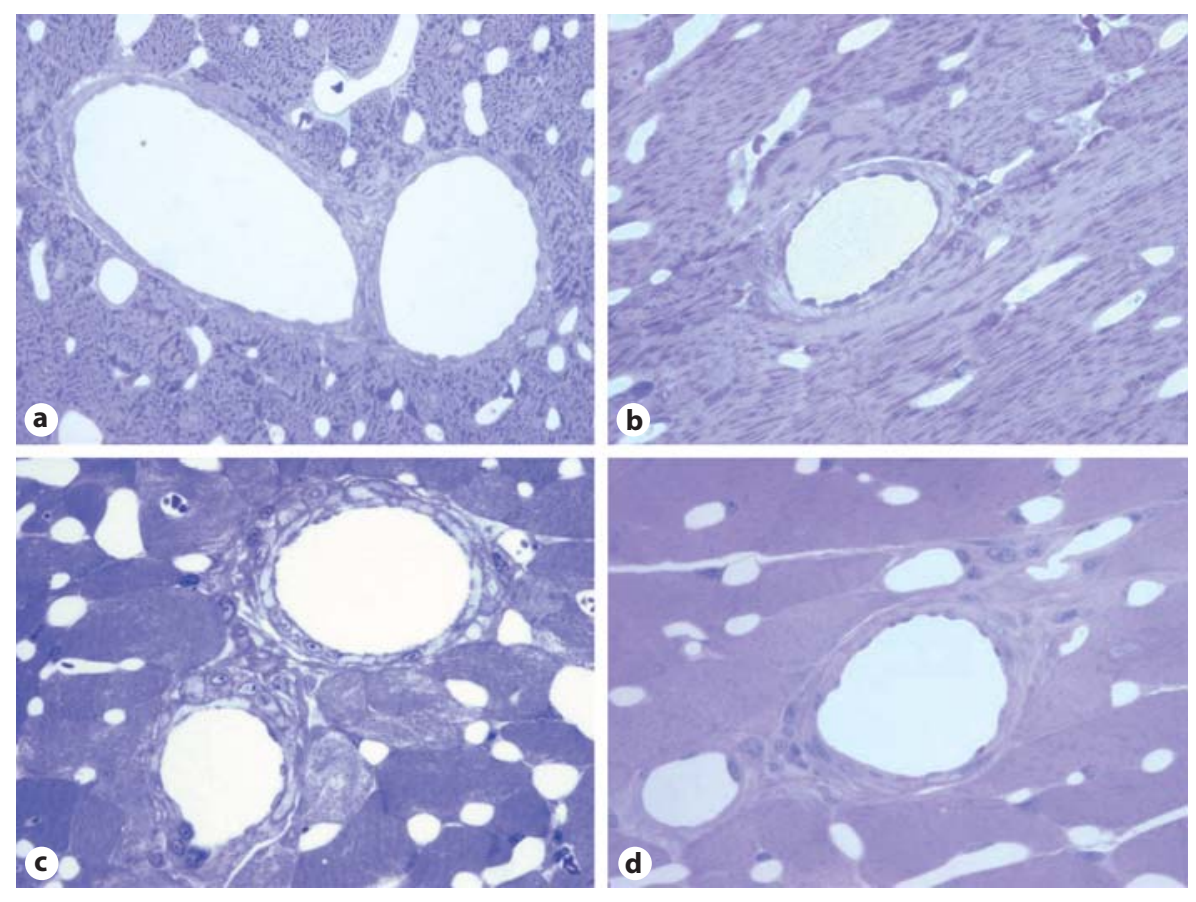

Table 2. Intramyocardial arterioles in the LV

\begin{tabular}{lllll}
\hline Group & $\begin{array}{l}\text { Wall:lumen ratio } \\
\mu \mathrm{m} / \mu \mathrm{m} \times 10^{-3}\end{array}$ & $\begin{array}{l}\text { Wall thickness } \\
\mu \mathrm{m}\end{array}$ & $\begin{array}{l}\text { Lumen } \\
\text { diameter, } \mu \mathrm{m}\end{array}$ & $\begin{array}{l}\text { Media area } \\
\mu \mathrm{m}^{2}\end{array}$ \\
\hline Sham-op (high salt; $\mathrm{n}=11)$ & $111 \pm 45$ & $3.08 \pm 0.72^{\mathrm{a}}$ & $29.3 \pm 6.1$ & $415 \pm 169$ \\
UNX (normal salt; $\mathrm{n}=9$ ) & $114 \pm 26$ & $3.65 \pm 0.92$ & $32.0 \pm 2.8$ & $635 \pm 210$ \\
UNX (high salt; $\mathrm{n}=8$ ) & $167 \pm 69$ & $4.69 \pm 1.41$ & $32.0 \pm 9.1$ & $796 \pm 433$ \\
UNX + LU 135252 (high salt; $\mathrm{n}=9)$ & $89 \pm 28^{\mathrm{a}}$ & $2.81 \pm 0.66^{\mathrm{a}}$ & $33.7 \pm 5.2$ & $438 \pm 208$ \\
\hline
\end{tabular}

A dose of $100 \mathrm{mg} / \mathrm{kg}$ body weight of LU 135252 was administered. Values are mean \pm SD.

${ }^{a} \mathrm{p}<0.01$ vs. UNX (high salt). Due to a different duration of the normal (18 weeks)- and high-salt (12 weeks) experiments statistical analysis does not include the UNX normal-salt group; the latter is given for comparison.

To exclude systematic sampling artifacts and selective reduction in the proportion of smaller arterioles, we plotted the cumulative frequency of sections as a function of vessel diameter. No significant differences between groups were found (fig. 2a). In contrast, as expected the cumulative frequencies of different classes of wall thickness showed a systematic shift to the right in the untreated UNX-SHRsp group (fig. 2b).

\section{Structural Parameters of Descending Thoracic Aorta (table 3)}

The structural parameters of the thoracic aorta did not differ in the three groups on normal salt (data not shown). The stereological measurements could not be performed in one aorta of the high-salt sham-op group due to technical problems. In high-salt animals UNX led to significant enlargement of the aortic lumen and media area and to thickening of the aortic wall. Treatment with LU 135252 completely prevented wall thickening and abrogated the increase in media area, while having no effect on lumen diameter. This led to a significantly lower wall:lumen ratio in the treated UNX compared to the untreated UNX animals (table 3). Electron microscopy revealed an increase in extracellular matrix and collagen fiber content in untreated UNX which was largely attenuated by LU 135252 (not shown). Furthermore, the num- 
Fig. 2. a Cumulative frequency of sections of intramyocardial arterioles as a function of vessel diameter. Note that there are no significant differences between groups. b Cumulative frequency of sections of intramyocardial arterioles as a function of vessel wall thickness. Note a systematic shift to the right in untreated salt-loaded UNX-SHRsp.
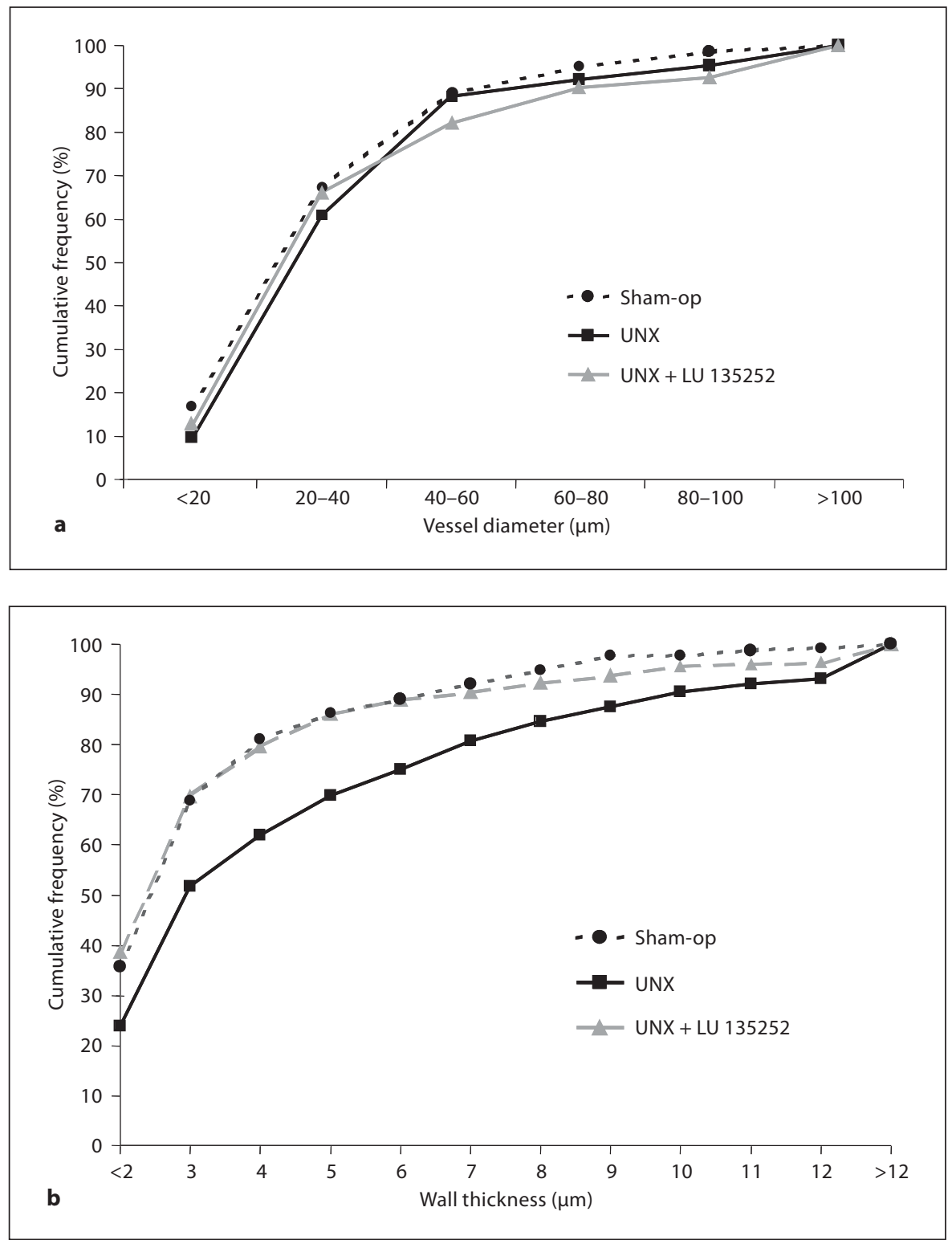

Table 3. Descending thoracic aorta

\begin{tabular}{lllll}
\hline Group & $\begin{array}{l}\text { Wall: lumen ratio } \\
\mu \mathrm{m} / \mu \mathrm{m}\end{array}$ & $\begin{array}{l}\text { Wall thickness } \\
\mu \mathrm{m}\end{array}$ & $\begin{array}{l}\text { Lumen area } \\
\mathrm{mm}^{2}\end{array}$ & $\begin{array}{l}\text { Media area } \\
\mathrm{mm}^{2} \times 10^{-2}\end{array}$ \\
\hline Sham-op (high salt; $\mathrm{n}=10)$ & $0.07 \pm 0.07$ & $116 \pm 13^{\mathrm{b}}$ & $1.92 \pm 0.41$ & $63 \pm 13^{\mathrm{d}}$ \\
UNX (normal salt; $\mathrm{n}=10)$ & $0.07 \pm 0.01$ & $176 \pm 32$ & $2.05 \pm 0.21$ & $87 \pm 6$ \\
UNX (high salt; $\mathrm{n}=8$ ) & $0.08 \pm 0.01$ & $161 \pm 27$ & $3.20 \pm 0.39^{\mathrm{c}}$ & $114 \pm 22^{\mathrm{c}, \mathrm{d}}$ \\
UNX + LU 135252 (high salt; $\mathrm{n}=10)$ & $0.07 \pm 0.01^{\mathrm{a}}$ & $128 \pm 28^{\mathrm{a}}$ & $2.90 \pm 0.39^{\mathrm{c}}$ & $88 \pm 13$ \\
\hline
\end{tabular}

A dose of $100 \mathrm{mg} / \mathrm{kg}$ body weight of LU 135252 was administered. Values are mean \pm SD.

${ }^{\mathrm{a}} \mathrm{p}<0.05 ;{ }^{\mathrm{b}} \mathrm{p}<0.01$ vs. UNX (high salt); ${ }^{\mathrm{c}} \mathrm{p}<0.001 \mathrm{vs.} \mathrm{sham-op;}{ }^{\mathrm{d}} \mathrm{p}<0.01 \mathrm{vs}$. UNX + LU 135252 (high salt). Due to a different duration of the normal (18 weeks)- and high-salt (12 weeks) experiments statistical analysis does not include the UNX normal-salt group; the latter is given for comparison. 
ber of elastic lamellae was increased in UNX groups: UNX $10.0 \pm 1.07$ (high salt; $p<0.05$ vs. sham-op), $9.2 \pm$ 0.8 (normal salt; $\mathrm{p}<0.05 \mathrm{vs}$. sham-op), UNX + LU 135252 (high salt) $8.6 \pm 0.7$ [p $<0.05$ vs. sham-op; $p<0.05$ vs. UNX (high salt)], sham-op (high salt) $6.8 \pm 1.32$. In sham-op animals the architectural organization of elastic lamellae was regular. In contrast, it was irregular with fraying and fractures in untreated UNX. These structural alterations were partially prevented by treatment with LU 135252.

\section{Discussion}

This study examined for the first time the structural changes of the heart, intramyocardial arterioles and descending aorta that are caused by UNX of SHRsp. Interestingly, UNX had no effect on the aforementioned parameters under normal-salt conditions. Under salt loading however, UNX led to excess mortality and severe LVH. UNX caused expansion of the cardial interstitium and marked hypertrophic remodeling of intramyocardial arterioles and the descending thoracic aorta. We emphasize that these changes were presumably independent of $\mathrm{BP}$, as $\mathrm{BP}$ was not different between groups up to week 10. The BP difference during the last 2 weeks of the experiment was only small, albeit significant. Mortality and $\mathrm{LVH}$ were completely prevented by treatment with the $\mathrm{ET}_{\mathrm{A}}$ selective receptor blocker $\mathrm{LU}$ 1335252. $\mathrm{ET}_{\mathrm{A}}$ blockade prevented the hypertrophic remodeling of resistance vessels, i.e. intramyocardial arterioles and elastic vessels, i.e. the thoracic descending aorta. Under normal-salt conditions $\mathrm{ET}_{\mathrm{A}}$ blockade had no effect on LVH and structure of intramyocardial arterioles and the descending thoracic aorta. As $\mathrm{ET}_{\mathrm{A}}$ blockade did not lower BP in the UNX animals for most part of the study, $\mathrm{ET}_{\mathrm{A}}$-mediated effects play no major role in the genesis of hypertension in this model. $\mathrm{ET}_{\mathrm{A}}$ receptor-mediated effects do, however, seem to play an important role in target organ damage.

The experimental protocol requires some comment. The SHRsp rat is a model of severe hypertension where salt loading and UNX do not increase BP, but aggravate target organ damage and cause high mortality [4]. We failed to note arteriolar necrosis, i.e. malignant hypertension, in our experiment. Postmortem examination of the untreated UNX-SHRsp on a high-salt diet that died prematurely showed brain hemorrhage and gastric or duodenal hemorrhage, respectively. Of importance, renal damage is seen in this model. In a previous study [4], we found significantly lower serum creatinine and endoge- nous creatinine clearance values as well as higher urea values in untreated salt-loaded UNX-SHRsp as compared to $\mathrm{ET}_{\mathrm{A}}$ receptor blocker-treated or sham-op animals [4]. This could explain why there was some BP difference at the end of the high-salt experiment. Furthermore, this may be potentially important since cardiovascular remodeling occurs in renal failure. Even in advanced renal failure, however, much less remodeling was seen than in the present study [8] so that renal impairment in the present study is probably not an important confounder. More importantly, urine sodium excretion did not differ between $\mathrm{ET}_{\mathrm{A}}$ receptor blocker-treated and untreated UNX animals on high-salt diet, i.e. the degree of salt loading was comparable. This fact excludes the possibility that the effects observed in the LU 135252-treated group are artificial and the result of a different salt load.

UNX was performed to increase sensitivity to salt loading, similar to what was also shown in other models of hypertension such as the desoxycorticosterone acetate (DOCA)-salt hypertensive rat [9]. There is mounting evidence that under conditions of salt loading ET receptor blockade is more effective (and conversely the vulnerability to ET-mediated target organ damage increased) [1]. Interestingly, in the Dahl salt-sensitive rat LU 135252 has been shown to normalize the sodium-induced increase of ET-1 protein content and the structural alterations of the aorta, although $\mathrm{ET}_{\mathrm{A}}$ receptor blockade caused only minor reduction of systolic BP [10]. Furthermore, the morphological changes of mesenteric and renal small arteries were much less [11].

The LV weight:body weight ratio is an index of LVH and was significantly increased in untreated salt-loaded UNX-SHRsp as compared to sham-op animals. Treatment with LU 135252 completely inhibited LVH. This confirms findings in the Sabra rat model of salt-sensitive hypertension by Rothermund et al. [12]: they reported complete prevention of LVH and LV dysfunction, but in this model specific $\mathrm{ET}_{\mathrm{A}}$ receptor blockade reduced the increase of systolic BP by $50 \%$. Prevention of LVH may be due to inhibition of cardiomyocyte hypertrophy. In vitro studies documented that ET-1 is a potent growth factor which induces hypertrophy of cardiomyocytes [13].

The morphometric analysis of myocardial arterioles, i.e. resistance arteries, and of the aorta, i.e. an elastic artery, showed major benefit from $\mathrm{ET}_{\mathrm{A}}$ receptor blockade. The salient feature of the present study is prevention of wall thickening of intramyocardial resistance vessels by LU 135252 despite no major change of BP, as also found in the 5/6 nephrectomy model [8]. Conversely we had shown that despite similar normalization of BP antihy- 
pertensive agents had diverse effects on the structure of intramyocardial arterioles: ACE inhibitors or calcium channel blockers, but not a sympatholytic agent, inhibited arteriolar hypertrophy [6]. Complete prevention of arteriolar hypertrophy by LU 135252 suggests that BP-independent $\mathrm{ET}_{\mathrm{A}}$ receptor-mediated events play a major role in the genesis of wall thickening of intramyocardial arterioles in the salt-loaded UNX-SHRsp. Interestingly, $\mathrm{ET}_{\mathrm{A}}$ receptor blockade affected intramyocardial arterioles, but not capillaries, i.e. had no effect on capillary length density in the LV. Although only $\mathrm{ET}_{\mathrm{B}}$ receptors had been reported in human myocardial capillaries [14], Larouche and Schiffrin [15] as well as Amann et al. [16] reported that $\mathrm{ET}_{\mathrm{A}}$ receptor blockade prevented capillary rarefication in the myocardium of DOCA-salt hypertensive and 5/6 nephrectomized rats, respectively. We emphasize that the effect of LU 135252 on heart structures was selective, i.e. despite significant effects on intramyocardial arterioles, no significant effect on cardiac interstitial fibrosis and capillary length density was noted.

One might argue that lesser wall thickness in myocardial arterioles is an artifact resulting from less pronounced LVH. It is therefore important that similar reduction of the media area of the aorta was noted. In UNX animals the lumen of the aorta, but not of the intramyocardial arterioles was increased.

The beneficial effect of $\mathrm{ET}_{\mathrm{A}}$ receptor blockade seems to be largely independent of BP, at least when measured by tail plethysmography. We cannot exclude larger effects on $\mathrm{BP}$ which might be detected by telemetric monitoring.

It was not the purpose of this study to elucidate the cellular mechanisms involved in the response of arterial vessels to LU 135252. Both hypertrophy and hyperplasia of vascular smooth muscle cells (VSMC) have been implicated in the arterial wall thickening in hypertension and renal failure. ET-1 causes mitogenesis and hypertrophy in $\mathrm{VSMC}$ via $\mathrm{ET}_{\mathrm{A}}$ receptors $[17,18]$. Further studies will be required to establish whether less pronounced wall thickness of intramyocardial arterioles and aortic media area is due to diminished cell proliferation or increased apoptosis, or both. ET-1 increases mitogenesis and inhibits apoptosis in VSMC [19]. Accentuation of apoptosis by treatment with an $\mathrm{ET}_{\mathrm{A}}$ receptor antagonist in the aorta of the DOCA-salt hypertensive rat has been reported by Sharifi and Schiffrin [20]. The remarkable effectiveness of $\mathrm{ET}_{\mathrm{A}}$ receptor blockade on arterial vessels may be due to interruption of an autocrine loop. ET-1 upregulates expression and synthesis of ET-1 via the $\mathrm{ET}_{\mathrm{A}}$ receptor, thus establishing a vicious circle. Based on their data obtained in Dahl salt-sensitive rats Barton et al. [10] advanced the hypothesis that $\mathrm{ET}_{\mathrm{A}}$ receptor blockade prevents structural changes in salt-sensitive hypertension by lowering vascular ET-1 content and by improving endothelial cell function. The potential mechanisms underlying the beneficial effect of $\mathrm{ET}_{\mathrm{A}}$ receptor blockade are difficult to evaluate, because there are interactions between the ET and the renin-angiotensin-aldosterone systems so that mutual reinforcement of the systems is not excluded [21].

The categorization of LU 135252 as an $\mathrm{ET}_{\mathrm{A}}$ receptorselective antagonist is based on data provided by the manufacturer [5]. A cautionary note is appropriate, however, in view of a preliminary observation of Mulder et al. [22] indicating some interference with the $\mathrm{ET}_{\mathrm{B}}$ receptor at doses $>30 \mathrm{mg} / \mathrm{kg}$ body weight. Consequently, we cannot exclude a, presumably minor, blockade of the $\mathrm{ET}_{\mathrm{B}}$ receptor by the dose of LU 135252 used. The fact that plasma ET concentrations did not increase in LU 135252treated animals supports the assumption that blockade of the $\mathrm{ET}_{\mathrm{B}}$ receptor did not occur. This point, however, has more than academic interest: deletion of the $\mathrm{ET}_{\mathrm{B}}$ receptor (knockout mice), and presumably also blockade of the receptor, alter renal sodium reabsorption and possibly salt sensitivity [23].

The present study has certain limitations. Because a salt-loading protocol was used, the results cannot be extrapolated to hypertension-induced end-organ damage in general. The protocol was designed to investigate the development of vascular lesions, but did not assess the potential of $\mathrm{ET}_{\mathrm{A}}$ receptor blockade to reverse established lesions. It has to be pointed out that $40 \%$ of the untreated UNX animals on high-salt died before the end of the experiment so that the results reported might even underestimate the benefit from LU 135252.

There are important species differences in the ET system, particularly between humans and rodents [24]. It will therefore be important to clarify the role of $\mathrm{ET}_{\mathrm{A}}$ receptor stimulation in hypertension-induced cardiovascular remodeling of humans to assess the therapeutic potential of $\mathrm{ET}_{\mathrm{A}}$ receptor blockade [25].

\section{Acknowledgments}

The study was supported in part by Knoll (Ludwigshafen/ Rhein, Germany), and grants from the Faculty of Medicine, University of Heidelberg, and the IZKF Erlangen (A11). Günter Schiele was a member of the Graduiertenkolleg 'Nieren- und Kreislaufregulation' of the Deutsche Forschungsgemeinschaft. The skilful technical assistance of Monika Klewer, Stefan Söllner, Miriam Ramming, Zlata Antoni, Gudrun Gorsberg and Peter Rieger is gratefully acknowledged. 


\section{References}

1 Schiffrin EL: Vascular endothelin in hypertension. Vascul Pharmacol 2005;43:19-29.

2 Orth SR, Viedt C, Amann K, Ritz E: Endothelin in renal diseases and cardiovascular remodeling in renal failure. Intern Med 2001; 40:285-291.

3 Feron O, Salomone S, Godfraind T: Blood pressure-independent inhibition by lacidipine of endothelin-1-related cardiac hypertrophy in salt-loaded, stroke-prone spontaneously hypertensive rats. J Cardiovasc Pharmacol 1995;26(suppl 3):S459-S461.

4 Orth SR, Esslinger JP, Amann K, Schwarz U, Raschack M, Ritz E: Nephroprotection of an $\mathrm{ET}_{\mathrm{A}}$ receptor blocker (LU 135252) in saltloaded uninephrectomized stroke-prone spontaneously hypertensive rats. Hypertension 1998;31:995-1001.

5 Stumpf C, Goeck S, Unger L, Nebel M, Riechers H, Raschack M: LU 135252 shows high endothelin-A receptor affinity and selectivity and oral efficacy leading to reduction of neointima formation in collared rabbit carotid arteries (abstract). Naunyn-Schmiedebergs Arch Pharmacol 1997;355(suppl): R103.

6 Törnig J, Amann K, Ritz E, Nichols C, Zeier M, Mall G: Arteriolar wall thickening, capillary rarefaction and interstitial fibrosis in the heart of rats with renal failure: the effects of ramipril, nifedipine and moxonidine. J Am Soc Nephrol 1996;7:667-675.

7 Mattfeldt T, Mall G, Gharehbaghi H, Möller $\mathrm{P}$ : Estimation of surface area and length with the orientator. J Microsc 1990;159:301-317.

8 Nabokov AV, Amann K, Wesseis S, Münter $\mathrm{K}$, Wagner J, Ritz E: Endothelin receptor antagonists influence cardiovascular morphology in uremic rats. Kidney Int 1999;55:512519.

9 Dworkin LD, Levin RI, Benstein JA, Parker M, Ullian ME, Kim Y, Feiner HD: Effects of nifedipine and enalapril on glomerular injury in rats with deoxycorticosterone-salt hypertension. Am J Physiol 1990;259:F598F604.
10 Barton M, d'Uscio LV, Shaw S, Meyer P, Moreau P, Lüscher TF: ET(A) receptor blockade prevents increased tissue endothelin-1, vascular hypertrophy, and endothelial dysfunction in salt-sensitive hypertension. Hypertension 1998;31:499-504.

11 Li JS, Turgeon A, Schiffrin EL: Effect of chronic treatment with two different ET(A) selective endothelin receptor antagonists on blood pressure and small artery structure of deoxycorticosterone acetate (DOCA)-salt hypertensive rats. Am J Hypertens 1998;11: 554-562.

12 Rothermund L, Vetter R, Dietrich M, Kossmehl P, Gogebakan O, Yagil C, Yagil Y, Kreutz R: Endothelin-A receptor blockade prevents left ventricular hypertrophy and dysfunction in salt-sensitive experimental hypertension. Circulation 2002;106:23052308.

13 Ito $\mathrm{H}$, Hirata $\mathrm{Y}$, Hiroe M, Tsujino M, Adach S, Takamoto T, Nitta M, Taniguchi K, Marumo F: Endothelin-l induces hypertrophy with enhanced expression of muscle-specific genes in cultured neonatal rat cardiomyocytes. Circ Res 1991;69:209-215.

14 Dashwood MR, Timm M, Muddle JR, Ong AC, Tippins JR, Parker R, McManus D, Murday AJ, Madden BP, Kaski JC: Regional variations in endothelin-l and its receptor subtypes in human coronary vasculature pathophysiological implications in coronary disease. Endothelium 1998;6:61-70.

15 Larouche I, Schiffrin EL: Cardiac microvasculature in DOCA-salt hypertensive rats: effect of endothelin ET(A) receptor antagonism. Hypertension 1999;34:795-801.

16 Amann K, Münter K, Wagner J, Balajew V, Nabokov A, Hergenräder S, Mall G, Ritz E: Endothelin A receptor blockade prevents capillary/myocyte mismatch in the heart of uremic rats. J Am Soc Nephrol 2000;11: 1702-1711.
17 Ohlstein EH, Arleth A, Bryan H, Elliott JD, Sung CP: The selective $\mathrm{ET}_{\mathrm{A}}$ receptor antagonist BQ123 antagonizes endothelin-l-mediated mitogenesis. Eur J Pharmacol 1992;225: 347-350.

18 Kanse SM, Wijelath E, Kanthou C, Newrnan P, Kakkar VV: The proliferative responsiveness of human vascular smooth muscle cells to endothelin correlates with endothelin receptor density. Lab Invest 1995;72:376-382.

19 Shichiri M, Yokokura M, Marumo F, Hirata Y: Endothelin-l inhibits apoptosis of vascular smooth muscle cells induced by nitric oxide and serum deprivation via MAP kinase pathway. Arterioscler Thromb Vasc Biol 2000;20:989-997.

20 Sharifi AM, Schiffrin EL: Apoptosis in aorta of deoxycorticosterone acetate-salt hypertensive rats: effect of endothelin receptor antagonism. J Hypertens 1997; 15:1441-1448.

21 Pollock DM: Endothelin, angiotensin, and oxidative stress in hypertension. Hypertension 2005;45:477-480.

22 Mulder P, Richard V, Bouchart F, Derumeaux G, Münter K, Thuillez C: Selective $\mathrm{ET}_{\mathrm{A}}$ receptor blockade prevents left ventricular remodeling and deterioration of cardiac functioninexperimentalheartfailure.Cardiovasc Res 1998;39:600-608.

23 Ohuchi T, Yanagisawa M, Gariepy CE: Renal tubular effects of endothelin-B receptor signaling: its role in cardiovascular homeostasis and extracellular volume regulation. Curr Opin Nephrol Hypertens 2000;9:435-439.

24 Davenport AP, Nunez DJ, Brown MJ: Binding sites for ${ }^{125}$ I-labelled endothelin-1 in the kidneys: differential distribution in rat, pig and man demonstrated by using quantitative autoradiography. Clin Sci 1989;77:129-131.

25 Barton M, Mullins JJ, Bailey MA, Kretzler M: Role of endothelin receptors for renal protection and survival in hypertension: waiting for clinical trials. Hypertension 2006;48:834-837. 